\title{
Peer Support and Well-Being: Exploring the Impact of Peer-Led Induction on Male Prisoners Ed Schreeche-Powell
}

\begin{abstract}
:
Implemented throughout the prison estate in England and Wales, peer-led induction aims to help people who are imprisoned deal with the challenges of transfer and transition between custodial institutions. As a power-sharing initiative, the study utilises interviews with prisoner mentees and prison induction officers to explore this reconfiguration of penal power, as well as evaluate its impact on the experience of imprisonment and on the wellbeing of adult male prisoners in the early days of custody following transfer. It identifies and explores the thematic concepts of tick-box cultures, information sharing and knowledge management, responsibilisation and iatrogenesis. It challenges the accepted idea that peer induction automatically results in better outcomes for prisoners, emphasizing the often unintended harmful outcomes experienced by those undertaking the peer-induction.
\end{abstract}

Keywords: peer-sort; well-being; iatrogenesis; tick-box; responsibilisation; information sharing; knowledge management

\section{INTRODUCTION}

'Prisoners lives matter' is a mantra that has been adopted by some, while overlooked and perhaps even neglected by many. Since the development of the liberal penological consensus, the mental health needs of the prisoner population have been described as an "important consideration" (Jewkes, 2007). However, the realities of mental health in prisons and that of prisoners sits in stark contrast to such ideological statements.

The World Health Organisation (WHO, 1998, p. 1) defines mental health as "a state of well-being in which every individual realises his or her potential, can cope with the normal stresses of life, can work productively and fruitfully and can contribute to his or her community". However, this notion is challenged by Jewkes (2007, p. 384) who suggests that "only one in ten of the prison population is not experiencing some form of diagnosable disorder". In an earlier edition of the Journal of Prisoners 
on Prisons, Walby (2014, p. 85) explores the experience of imprisonment and the associated pains from the perspective of prisoners, identifying how prisons are synonymous with deprivation causing captives to experience an "assault on the self'. This often manifests itself in a wide range of mental health issues, the exacerbation of underlying conditions, and/or increased and prevalent self-harm and suicidality in the prison estate across England and Wales. These issues and conditions all serve to indicate a prison system in the midst of a "mental health crisis" (Allison, 2018; National Audit Office, 2017).

There are various triggers for a decline in mental health and well-being. Prison transfer and reception into a new custodial setting are both examples of aggravating factors (Liebling 1992). Current safer custody strategies recognize the importance of peer support in the custodial environment, and it is becoming an increasingly prominent facet in the promotion of health and well-being, as well as the reduction of deaths by suicide and self-harm in custody (NOMS, 2015; Snow and Biggar, 2006; Davies 1994; Woodall et al., 2015). Peer-based intervention is an umbrella term covering a range of lateral interventions delivered by and for service users that involves providing counselling, education, support, and pro-social modelling (McHugh, 1995). In prison settings, these are programmes, interventions and schemes that are designed, facilitated or delivered by fellow prisoners for their peers. One such frontline peer intervention is induction, an introductory process that every prisoner undergoes upon arrival at prison. Although it is still very much in its infancy, research into peer intervention in custodial settings is gathering moment. However, many critical interventions and schemes utilizing peers in service delivery remain without study and evaluation (Woodall, 2018; South et al., 2014; Fletcher and Batty, 2012). Developing a more extensive body of research will provide greater insight into the prisoner experience of incarceration for those in the criminal justice sector and, therefore, enable the design of policy, procedures, interventions, and measures that are needsbased and best suited to mitigate stressors and triggers of prisoner mental health issues. This will help promote more positive prisoner experiences in these areas.

A prison induction intervention is required to ensure that prisoners have the appropriate level of care, support and continuity to assist them when transitioning to a new establishment. This is achieved in two ways. Firstly, "prisoners know and understand their entitlements and responsibilities, and 
how to access support and facilities available to them... in a manner relevant to their individual needs" (NOMS 2015, p. 7). Secondly, "all prisoners undergoing induction must be treated decently and safer custody requirements must be followed at all times and risks appropriately managed" (ibid). As a frontline intervention, peer-led induction has the potential to have a profound effect on a prisoner's experience of both transfer and well-being.

However, despite $7 \%$ of the prison population being involved in some form of peer-support role (South et al., 2014) and prison transfers being a frequent event, with 76,502 recorded inter-prison transfers in 2017 alone (MOJ, 2018), there are no substantial studies documenting the impact of peer-led induction in England and Wales to date. The only exception is a report into a multisite pilot 'Induction Insiders Scheme' from 2002 (Woodall, 2018; Teers, 2005). Furthermore, there has been no substantial evaluation of the impact and experience of the process that such an intervention has in the context of reception into a new custodial establishment following inter-prison transfer.

Although these interventions are often perceived as a positive indication of institutional intent, they can actually perpetuate frustrations. There is increasing attention being paid to the idea that prevention programmes within the criminal justice system can cause physical, emotional and psychological harm. Cohen (1982) applies the concept of "iatrogenesis" in a criminological context to illustrate both the "paradoxical counter productivity' of institutions, and how interventions designed with the best of intentions may create unintended consequences and poor results. When considering interventions in custodial settings, there are a number of potential underlying issues that cause problems ranging from poor design, deficiencies in facilitation and delivery, negative staff and prisoner cultures, and austere conditions of confinement. Despite these evident issues, recent research into the mental health and well-being of prisoners has further identified a "worrying lack of large-scale intervention studies" (Jarrett, 2018, n.p.).

This study explores the impact of peer-led induction on the mental health of prisoners by addressing this lack of research, employing a qualitative approach to:

- Identify the variety of context-specific factors, stressors, triggers and difficulties experienced by male prisoners following prison transfer, how they are experienced, and their impact on prisoner well-being; 
- Determine from the mentee and prison officer perspective the elements of the induction process that work to address and mitigate these difficulties;

- Evaluate the impact of the current peer-led induction initiative on the well-being of people who are imprisoned to ultimately establish if the induction intervention impacts on the well-being outcomes of mentees; and

- Explore the perspectives and experiences of the induction intervention and processes from prison staff engaged in the delivery and supervision of this intervention.

Conceived as a power-sharing initiative with the capacity to reconfigure penal power, the analysis applies 'new wave' theory and conceptualizations of 'weight and tightness' (Crewe, 2011; Crewe et al., 2014) in the context of peer-led induction. These concepts explore the interaction between the application of power in custodial setting and how it manifests in the experience of imprisonment and, more specifically, the mental health and well-being of prisoners subject to them.

The present article begins by providing a critical review of the subjectspecific literature and is organized into three distinct sections covering: (i) the mental health and well-being of prisoners in our prisons; (ii) pain, power, weight and tightness in the prisoner experience of imprisonment; and (iii) peer-led interventions. The methodological approach adopted in this study is also outlined and the findings are critically discussed. The article concludes with a review of the study and its implications.

\section{THE MENTAL HEALTH AND WELL-BEING OF PRISONERS IN OUR PRISONS}

Sykes (1958) argues that the pains of imprisonment challenges an individual's self-esteem and endangers their mental health. There is a high prevalence of mental health and well-being problems among people within the criminal justice system. All category of prisoners experience high levels of difficulty with their mental health and well-being (Peay, 2017). The prison population is subject to a variety of mental health stressors including prison transfer, which can trigger self-harming or suicidal behaviour (Liebling, 1992).

The extent of mental health and well-being issues in prisons is illustrated in the 12 calendar months leading up to March 2018 in which 
46,859 instances of self-harm were reported, representing an increase of $16 \%$ year-over-year (MOJ, 2018). During this period, the number of selfharming individuals increased $8 \%$ to 11,854 . For incarcerated men, there was 467 self-harm incidents per 1,000 male prisoners, representing a 14\% increase from the previous year. The number of self-harming male prisoners requiring hospital treatment increased by $12 \%$. There were also 79 selfinflicted deaths of men in custody in a 12-month period (Jail Mail, 2018; MOJ, 2018). This paints the picture of a prison system in the midst of a mental health crisis with the trend being continual decline.

Prisons are under increasing pressure that stems largely from austere measures, making it more challenging to manage prisoner mental health and well-being. Liebling (1999) argues that these issues culminate in immense distress and evidence the "corrosive and demanding nature of imprisonment". This endured suffering leads to what Giddens (1984) terms a state of "ontological insecurity" that can overwhelm an individual's psychological coping mechanisms. While genuine efforts have been made to improve outcomes relating to suicide prevention, safety and decency, these attempts are being eroded by austere conditions, and the prioritization of "efficiency and less visionary models of imprisonment" (Crewe and Liebling, 2017, p. 909).

It is postulated that prisons must have an ethos that is fundamentally good for the basic mental well-being of those imprisoned (Fraser et al., 2009). Peer support and peer-led induction are interventions with the capacity to support this ethos and promote positive outcomes for prison and prisoner. Criminological research has emphasized the idea that prisons can positively influence the mental health and well-being of their populations through these and similar initiatives (Fletcher and Batty, 2012; South et al., 2014). Fraser and colleagues (2009, p. 139) note that "good prisons are good for prisoners and public health and safety as those having support and intervention and their issues addressed are less likely to engage in refractory behaviour and commit crime upon release". There is a clear indication of positive outcomes stemming from a more positive prison regime with peer intervention being one strategy that both underpins and contributes to the manifestation of this range of prisoner outcomes. 


\section{PAIN, POWER, WEIGHT AND TIGHTNESS}

The work of Sykes (1958) acknowledges the "pains of imprisonment" experienced by prisoners are influenced by how prison management exercises their power. These pains have traditionally been experienced through a loss of autonomy and control over sexual and personal relationships, a lack of material possessions, and the erosion of personal security, all of which have a crushingly negative impact on the prisoners' sense of self.

Downes (1988) built upon this theoretical framework by postulating that the extent to which imprisonment is experienced as damaging and repressive depends upon a range of factors that stem primarily from power application. Through the exercise of authority and power, prison management is a significant variable in shaping the experience of those imprisoned (Crewe et al., 2014). When there is the belief among prisoners that the application of authority and power of prison management is fair and appropriate, there is often a more favourable response which subsequently elicits positive prisoner outcomes. However, previous theory has often automatically associated power with coercion. Theoretical frameworks have failed to adequately "reflect in relation to the concept of weight" (ibid) and made it "impossible to identify what forms of the exercise of penal power, and by whom, might be preferable to others" (McMahon, 1992, p. 215).

'Weight' is the commonly employed terminology those who are imprisoned use to articulate the psychological impact of their imprisonment, describing the degree to which their experience weighed them down (Crewe, 2011; Crewe et al., 2014). Historically, the concept of 'weight' is associated with its suppressive nature, rather than considerations of how differing power formations may bring about a range of positive outcomes such as support and 'buy-in' to the regime. For example, custodial regimes with the appropriate 'weight' and high legitimacy can promote personal well-being, whilst those based on coercive and interpersonal arrangements are likely to come at the expense of these factors. Good power, such as power used with care as opposed to power used with indifference, can achieve such positive outcomes. This contemporary theorization builds upon the foundations of Foucauldian theory which argues that power is not merely repressive, but can be productive and positive (Foucault, 1977; 2002). Good power can include the provision and delivery of counselling, education, support and 
pro-social modelling. Providing support to others imprisoned in situations that could trigger distress is shown to have favourable impacts in preventing deaths by suicide and self-harm (Davies, 1994; Liebling and Price, 1999). As such, Devilly and colleagues (2005, p. 219) suggests that prison-based peer-led programmes have something to offer correctional institutions.

\section{PEER-LED INTERVENTIONS}

Fletcher and Batty (2012) argue that a culture of 'doing more with less' has arisen partly due to increasingly austere prison conditions. Establishments are left seeking to bridge the gap between their institution on one side of the divide and prisoners on the other. They are unequivocal in presenting evidence in support of peer-support and power-sharing initiatives to deliver positive outcomes in custodial settings. However, these measures also further stretch an establishment's austerity depleted resources.

In prison settings, induction related peer support schemes are predominantly identified, recognized and delivered by 'Induction Insiders' or 'Induction Peer Support Workers'. Current suicide prevention measures recognize the importance of peer support as an increasingly prominent facet in the promotion of health and well-being. South and colleagues (2014, p. 44) found that there is evidence of positive benefits for recipients of peer interventions, arguing that "peer support helped prisoners practically, emotionally or both". Those who had used peer support reported using it as an avenue to "overcome feelings of anxiety, loneliness, depression and self-injury" (ibid, p. 47). However, the impact of mental health promotion in the context of induction is unexplored as of yet with regard to research.

Peer-Led induction requires input from prison and authority figures, which can potentially diminish the effectiveness and impact of the intervention (South et al., 2014). Prison staff cultures vary considerably and these variations have significant consequences for prisoners' quality of life. Crewe and colleagues (2011) state that prison staff cultures impact the way that staff use their authority, especially with regard to staff being deliberately 'heavy' and antagonistic, while disproportionately employing their power for a range of reasons including enjoying their position of power, perceiving themselves as being disliked by prisoners, as well as holding feelings of hostility and ambivalence towards the incarcerated. Downes (1988) 
suggests there needs to be serious investigation of those who are subjected to these different forms of penal power. Given the growing recognition of the substantial effect of imprisonment on both the short- and long-term mental health of prisoners, there are likely to be severe consequences for this lack of research into the impact of transfer and induction.

\section{METHODOLOGY}

For the purposes of this study, a qualitative framework was adopted as it fits appropriately with the constructionist and interpretive approach privileged. This approach makes space for the exploration of "the cultural, hierarchical, social and emotional dimensions of life and work in prison" and allows for the development of "storytelling and narrative accounts to humanize both the research process and the penal world" (Liebling, 2014 in Beyens et al., 2015, p. 73). This creates a "humanistic style of research which tries to depict the painful and emotional aspect of the social practices we study" (Liebling, 2014, p. 481). The study aims to observe and describe the connection between the mental health and well-being of the prisoner interviewees and the deepseated psychological perspectives they held in relation to their experience of imprisonment and the intervention. These experiences often produce embedded and evocative feelings that are difficult to encapsulate and harness. The prisoner interviewees were allowed to express their feelings in a manner that they are comfortable with, including through an open narrative drawing on vignettes, experience and their perceptions. This approach provided the benefit of collecting a nuanced and in depth set of data.

The methodology comprises of a qualitative impact evaluation study incorporating a focus on the impact and outcomes of the peer-led induction intervention. An 'open prison' in the South of England is the site where all participants experienced the induction intervention. Data collection took place in the form of semi-structured interviews with six ex-prisoners who experienced both transfer and engaged with the peer-led induction. Participants were recruited through an advertisement posted online by The Prisoners Education Trust and Learning Together alumni networks. Figure 1 provides contextual demographics of the participants. The research also includes two officers who are engaged in the delivery and facilitation of this intervention who were identified and approached to take part in the study. 


\begin{tabular}{|c|c|c|c|c|c|c|c|c|c|c|}
\hline $\begin{array}{l}\text { Particionot } \\
\text { Pasevidonom }\end{array}$ & Aas & $\begin{array}{l}\text { Lenath of } \\
\text { Establishment } \\
\text { Residence }\end{array}$ & $\begin{array}{l}\text { Eirstsenteose } \\
\text { of } \\
\text { Imprisonment? }\end{array}$ & $\begin{array}{l}\text { Number of } \\
\text { previous } \\
\text { imprisonments }\end{array}$ & $\begin{array}{l}\text { Sentence } \\
\text { Impe }\end{array}$ & $\begin{array}{l}\text { Sentense } \\
\text { (5) Thariff } \\
\text { m } \\
\text { Lenoth }\end{array}$ & $\begin{array}{l}\text { Lengthe of } \\
\text { Iime } \\
\text { Imorisened } \\
\text { in Total } \\
\text { during } \\
\text { ifospon }\end{array}$ & $\begin{array}{l}\text { National } \\
\text { Odentifx }\end{array}$ & Ethoicitox & Betialon \\
\hline Rich & 52 & .2 Years & Yes & 0 & Lte & 14 Year & 14 Years & Bention & $\begin{array}{l}\text { Whic: } \\
\text { Englien }\end{array}$ & Crviatian \\
\hline steve & 47 & .2 Years & No & 1 & Lete & 19 Year & 23 Years & Bentien & $\begin{array}{l}\text { Biack } \\
\text { Atrican }\end{array}$ & Constian \\
\hline Paut & 37 & +2 Years & Yes & 0 & Le & $\begin{array}{l}16 \text { Year } \\
\text { (i) }\end{array}$ & 16 Years & Bentan & $\begin{array}{l}\text { White: } \\
\text { Englian }\end{array}$ & Musim \\
\hline James & 44 & $13-24$ Mens & No & 4 & We & a Year (n) & 18 Years & Jameican & Cand & Constan \\
\hline Andy & 36 & 13.24 Moss & No & 3 & Det & $\begin{array}{l}15 \text { Year } \\
\text { (5) }\end{array}$ & Months 9 & Indian & Andan: & sach \\
\hline Nan & 29 & 7.12 Mens & Yes & 0 & Det & $\begin{array}{l}\text { 8 years } 6 \\
\text { Mens } \\
\text { (s) }\end{array}$ & Months 6 & Englian & $\begin{array}{l}\text { Deack: } \\
\text { British }\end{array}$ & Musim \\
\hline
\end{tabular}

Figure 1: Ex-Prisoner Demographics

This is a hard to reach population that is being investigated in this study. Under such circumstances, even a small empirical investigation with a limited sample size both develops and adds to the minimal literature on the experience of imprisonment in relation to the transitional stages of custody and the use of power sharing initiatives. While a larger sample size would have been welcomed, securing the number of participants involved is a significant achievement in itself and one which is commensurate to elicit the richness of experience required to explore the aims and objectives of the study.

The semi-structured nature of the interviews allowed for the exploration of experiences and topics that both the researcher and interviewee feel are pertinent. This facilitates the attribution of meaning to the mentees, prison staff environment, their experience of the process, and measure improvements and/or reductions in the well-being of the prisoner. This also allows for the exploration of the nature of the induction intervention on prisoner mental health, as well as the identification of the various factors that may be experienced, potentially influencing impact. The qualitative interview questions were designed to evoke experiences of transfer and the process of induction relating to the concepts of relationships, support, fairness, safety, well-being, family contact, quality of life and mental health. These questions were built upon the research of Liebling (2004) who had earlier identified these topics as key concerns when exploring and attempting to encapsulate prisoner experiences of imprisonment. These questions elicited rich data regarding mentee and prison staff experience of transfer and the process of induction, and also identified process aspects that work, as well as those that do not. 
The interviews focus purely on the experiences and perspectives of the prisoner mentees and prison staff. Interviews in this 'contextual uniqueness' produced 'thick description' of experience, which are possibly transferable (Gertz, 1973), and underpin the understanding of the prisoner and staff social experience. Through the methodological techniques employed, the transcription revealed a range of ideas and notions that were identified and shared by the interviewees. These identified commonalities are best encapsulated and categorized thematically into five distinct concepts: tick-box exercise, responsibilisation, information sharing, knowledge management and iatrogenesis. Each are explored in turn below.

\section{INDUCTION AS A TICK-BOX EXERCISE}

Everyone is out for themselves... They ain't interested in helping us settle in and adjust.... They are only interested in what suits them (Andy).

The most prevalent theme that emerged from the fieldwork was concerned with the motivations of the peers leading induction, as well as the prison staff overseeing the process. These comments suggest that there is a selfserving motivation and 'tick-box culture' that exists surrounding the induction process. Former Justice Sector Ken Clarke historically grumbled about the tick-box culture (The Guardian, 2013) that keeps prison officers from dealing with prisoners. Tick-box culture is defined as a bureaucratic and external imposition on professional working conditions that can be found in organizations around the world (The Guardian, 2013). In prison, tick-box culture encourages a disproportionate emphasis on rule following, rather than actually helping the prisoners housed in the institution. It also creates a distinct lack of motivation for prison staff to deal with prisoners due to an apparent prioritization of self-serving objectives and goals. The following statements by officers capture this issue:

As long as we satisfy the first-night requirements, that's the priority (Officer A).

We have to follow the guidelines as set down by the PSI [Prison Service Instruction] and management (Officer B). 
What are these requirements? The prison service is governed by a range of policy documents known as PSI, which contain detailed information regarding the rules, regulations and guidelines that must be followed in operational contexts. With regard to reception into custody, the first night in custody and the induction process, PSI 07/2015 (NOMS 2015) lay out the procedures to be followed, mainly that "prisoners are kept safe and supported during their first night in prison" and that their immediate needs are met. It goes on to highlight the significant stress experienced by prisoners when family and community links are broken, and their future is uncertain. The same PSI stipulates that "[m]any self-inflicted deaths and self-harm incidents occur within the first 24 hours, the first week, and the first month" (ibid). Emphasis in custody is therefore accordingly placed on "tackling safer custody issues during the first 24 hours and beyond is likely to produce most benefit in this early period" (ibid). The PSI states that "peer supporters may offer additional help to prisoners, particularly during the first night" (ibid, p. 7). As articulated by Officer A: "The main thing is we check they ain't gonna cut up or string up".

The PSI suggests that "[p]risoners assessed as being at risk of suicide or self-harm should have support identified and managed", which is critical because "prisoners returning to custody are at increased risk of suicide/selfharm, and the risk occurs with transferred prisoners" (ibid, p. 13). Given that there are significant and complex circumstances that accompany male prisoners received into custody which exacerbate this risk, the importance of their management is paramount. Staff must be aware of and comply with these important aspects of safer custody policies.

While this assessment was consistently carried out, participants all described the process as feeling mechanical. Interviewees reported that once staff were satisfied that they were not going to self-harm or commit suicide, they moved along without addressing underlying risks, including anxiety, stress and depression, which all of the interviewees declared themselves as experiencing. The interviews with both staff and prisoners suggest that these negative emotions were not given appropriate consideration once a prisoner reported not feeling suicidal or willing to carry out self-harm. Being in an open prison does not in itself mitigate or nullify the effects of imprisonment. Indeed, being in an open prison comes with its own pains of imprisonment that result in a degree of psychological stress and insecurity.

The prison staff appear to satisfy a tick-box approach with regard to managing self-harm and suicidality without bothering to explore the mental 
health issues that these often manifest from. As one prisoner laments:

All I needed at the time was a bit of support and guidance, but all I got was a load of staff and peer supporters who made me feel like an inconvenience and a pain in the arse - completely disinterested... No people skills... Just made me feel even worse than I already was (Paul).

It is widely acknowledged that prisoners often have complex needs and circumstances including mental health and substance abuse issues, a lack of support network, and poor socio-economic status. This is reflected throughout the PSI, which recognises that some prisoners received into prison "will need support and assistance to resolve urgent and immediate issues arising as a result of their imprisonment and which adversely affect their lives (or the lives of others) outside the prison" (NOMS, 2015, p. 9). The PSI states that the prison establishment should "help prisoners to uphold their immediate responsibilities to others by assisting them to solve immediate problems and make arrangements to cover the time they will spend in prison" (ibid). During the initial interview, "staff must take time to listen to prisoners and offer them help and support in resolving or managing their most urgent issues that arise directly as a result of their imprisonment, time and resources must be available to resolve issues that cannot be left unresolved providing personal help and support to prisoners as needed" (ibid). Given that transfer and transition are key stressors for prisoners, these mandated PSI actions serve as fundamental tools to ensure that the prisoners feel more secure by reducing anxiety that may stem from their fears, concerns and uncertainties. This can potentially have a positive impact on the prisoners' mental health and well-being. There are challenges, however, as Officer A describes:

Ideally, we would like to spend more time with them and do more, but we just don't have the time... the best we can do is a quick first night interview to cover the basics that we have to do...

Officers stated that they could and would like to do more, but they did not have the time available to do so. They were reduced to offering a sparse provision that failed to allay concerns and issues of the new arrivals or provide the level of support that inductees expected. The prisoners interviewed stated that this failure directly contributed to elevated anxiety and stress at times when they were already struggling to cope. 
The induction PSI mandates that first night staff should be supported by Induction Insiders in this task. However, alarming deficiencies in this area indicate a distinct lack of interest from the peers in assisting with this process and a prevalent perspective that they were only interested in having their paperwork signed-off, indicating to others that they had "done their job". On this point, James notes:

The peers couldn't wait to get me out the door so that they could crack on with cooking their dinner and playing pool... Every time I asked a question, they just fobbed me off and told [me] I'd figure it out as I went along.

Prison policy recognizes that prisoners received into custody may find the early days and period of adaptation intense and often fraught with anxious concern. The guiding PSI accordingly states that "some prisoners may need additional support and assistance in understanding and adapting to the prison environment and that all prisoners new to custody and new to the establishment must be provided with key information relevant to their first few days in the establishment" (NOMS, 2015, p. 10).

The findings of this study, however, show that this was not the case. The majority of those interviewed reported that these guidelines were not fully met during the first night by induction staff and peers. Interviewees stated that while induction staff and peers met with the mentees and ticked the box, they failed to deliver the prescribed information. Many reported simply being told the roll call times, mealtimes, and being asked whether or not they had any desire to self-harm or commit suicide. Some were told they would find out more about the prison the following day whilst others were given a few pieces of information on paper, including a timetable of induction events over the coming seven-day period. From there, they were then sent on their way. It is apparent that staff and peers carried out a rather mechanical task to partially satisfy a routine guideline, rather than fulfill and deliver a commensurate needs-driven model. As Steve explains:

The screws want an easy life and to cover their arses, and the peers just wanna look good to the screws and the parole board and OMU [Offender Management Unit]. 
The officers interviewed emphasized that the large amounts of paperwork not only create huge time constraints impacting their ability to do their job, but also create a culture whereby staff seemingly do everything by the book, rather than using their own professional judgement. The shackles of unhelpful government targets and guidelines require adhering to centrally prescribed ways of working, thereby diminishing any prospect of local level autonomy in aspects of the practice. However, the majority of mentees interviewed expressed the perspective that officers and peers 'hid behind' the sentiment that they were bogged down by paperwork and, as a result, did not have the time to deliver the intervention appropriately. The prisoners interviewed stated that their perception was that the officers and peers simply preferred not to fully carry out their duties as prescribed. Rich explains:

They ain't got no interest going through the information with you... there's loads of it... All they want is your signature to say you've been given it and read it... They are meant to go through it with you, but they can't be bothered... I can't blame them to be fair... There's so much I wouldn't be fucked to go through the spiel time and time again.

The peers delivering induction claim to be similarly bogged down by excessive paperwork and tick box culture. The dominant consensus, however, was that they also hid behind this notion and were disinterested. The comment from ex-prisoner Rich (quoted above) encapsulates the sentiment of other ex-prisoner participants.

Tick box culture means there is too much emphasis on following guidelines and rules instead of actually helping the prisoners transitioning into the prison in a more needs-focussed manner as a 'one size fits all' approach appears to be in place. This reduces the autonomy of the induction staff and peers, and fails to allow either to think for themselves or to deliver a needs-driven model for induction. The system is resultantly full of people 'doing things right', rather than 'doing the right thing', which is a phrase Munro (2010) used when describing the tick box culture evident in our school system. Relentless top-down government targets, along with too many forms and procedures, are preventing prison staff from providing transitioning prisoners the help they need and assessing whether that help has made an actual difference. 
The two officers interviewed both expressed that there was a distinct lack of time to focus on the care of transitioning prisoners. It is a combination factors including austere conditions, a diverse set of prisoners with complex needs, tremendous pressure from management to do more with less, as well as comply with rules and regulations that underpin a culture that is far from being effective at promoting positive well-being for prisoners. As a result, it is not surprising that officers welcomed the use of peers leading the induction and regularly contracted out to them in order to free up their time and "make their life easier" (Officer B). Staff were more concerned with these priorities, rather than the inductee's individual needs. The danger of this power-sharing is that the peer support workers integrated into the operational structure that is diminished by a lack of careful delegation of such power results in what Liebling and Crewe (2017, p. 907) refer to as power being handed to peers in an "informal, collusive and unaccountable" manner. Paul outlines the consequences of such an arrangement:

It's the induction orderlies who rule the roost on A Wing... The screws leave it up to them to do what they want 'cos it means they don't have to do fuck all themselves and in return they let them [peers] do whatever they like and give them their little perks.

The prisoner hierarchy is operationalized with those prisoners with credibility among staff (and sometimes their peers) being given the influential work placement as an induction insider in exchange for them exerting their influence over the new inductees as a form of governance. This is evidenced in the research findings, including diminished staff authority, a steeper prisoner hierarchy and imbalances of power in the sharing initiative. These dynamics all serve to reinforce and exacerbate triggers and stressors identified by ex-prisoner participants that create the impression of what Dilulio (1987) terms a 'corrupt alliance'. As noted by Liebling (2017, cited in Parliament, 2017), this leads to consequences:

You do not get any of the things you are really after, such as prisoner well-being and personal development, which we know are linked to all the outcomes we are interested in, until all the basic hygiene things, such as policing and security, staff professionalism, respect, humanity and safety, are in place. 
In such cases, the establishment lacks a more comprehensive needs-driven approach to its compliance procedures and instead follows a tick box mentality. According to the insights collected through the interviews, the establishment focuses on simple compliance within a rigid set of rules, which ultimately presents a significant challenge for the Prison Estate to produce positive prisoner outcomes. Staff explain that this issue is due to unrelenting governmental pressure through target meeting and audit consideration. This approach hinders the development of a more positive culture and a needs-based model that would promote the best outcomes for the prisoners.

The ex-prisoner participants repeatedly identified factors, including distance from family, safety in the new establishment, uncertainty over regime and protocols within the new establishment, as well as a lack of support and information, as being significant stressors that trigger elevated levels of anxiety and insecurity, thereby impacting their ability to function and their general well-being. They identified that a needs-driven induction model should address these issues and the PSI itself states that the needs of prisoners should be met. However, this intentional aspect of such a model is not evident in this establishment. On the contrary, the overarching theme of care and support is largely eroded and precluded by the enduring nature of a tick-box culture. This self-serving mentality on the part of prison staff and peer supporters can only lead to increasing the psychological onerousness and ontological insecurity of prisoners, leaving them feeling like they are swimming in a shark tank (Liebling and Arnold, 2004).

\section{A DEPARTURE FROM ARSE-WIPING: 'RESPONSIBILISATION'}

Whenever the screws and peers couldn't be asked to answer a question or help out or do something for me they just kept saying it was up to me to find out, or it was my responsibility to find out/sort it (Paul).

...You need to start doing things for yourself... [You're] gonna be going on day release in the community soon and you ain't gonna have no one to wipe your arse for you then. That was the excuse they kept giving me not to do shit (Steve). 
The above quotes encapsulate a perverse form of responsibilisation. This attitude purports to enable and empower the prisoner when, in fact, many interviewees felt it was a convenient excuse not to provide much-needed support. Instead of giving time, knowledge, information and support, this strategy allows the peer supporters and prison induction staff to pass the buck by shifting responsibility to prisoners. This purported responsibilisation of prisoners sits in direct contrast to the overall purpose and spirit of the induction process of reducing anxiety, self-harm, and promoting well-being.

Although being granted a semblance of autonomy and choice under the guise of 'responsibilisation', Giddens (1991 cited in Crewe, 2011, p. 519) carefully observes that "the prisoner is exposed to a greater degree of risk... this opening up of possibilities provokes feelings of anxiety and powerlessness". A few study participants reflected on this:

What's the point of having peers and staff if they ain't gonna help?... It just stressed me out even more. I didn't know what to do or how to go about doing it when I did... Just made everything so fucking hard (Alan).

Peer support was a myth... In a strange environment after years in a different nick, and I was told to crack on with it and figure things out myself... I just wanted to go back [to my previous prison] amongst what I knew... I was stressed to fuck by it all (Steve).

The research findings indicate that the most appropriate metaphor to characterize the impact of the responsibilising nature of the induction is arguably that of 'tightness', rather than 'weight'. Power in this context as applied by the induction prison staff and peer support who "[do] not so much weigh down on prisoners and suppress them", but rather engulf and smother them, coercing them to conduct themselves in particular ways (Crewe, 2011, p. 522). The following quotes reflect this lived reality:

They are on top of you all the time... Just waiting to fuck you over (Rich).

You have to do it one way or the other... (James).

This notion of 'tightness' "captures the feelings of tension and anxiety generated by uncertainty, and the sense of not knowing which way to move, 
for fear of getting things wrong" (Crewe, 2011, p. 522). Rich describes how he experienced this phenomenon:

I spent most of the time in my cell 'cos I was so paranoid about getting shit wrong. I was treading on eggshells all the time.

The autonomy given by the establishment to its prisoners is restricted and constrained, and the "smack of firm government" is always ready to ensure this autonomy is actioned appropriately (Crewe, 2011, p. 523). The full weight of hard power is waiting in the wings when softer responsibilising strategies fail; soft power and self-regulation is ring-fenced by coercion. For example, attending induction is technically a voluntary endeavour. However, failing to attend or not engage appropriately can result in consequences to the progression and resettlement of prisoner, as Rich's comment below indicates:

You're given a piece of A4 paper - that's all - with an induction timetable on it... It's down to you to follow the induction timetable and go where it says at the time it says, if you don't know then the completion of your induction will be delayed, which means you'll be delayed moving off the wing and your progress will [be delayed] too.

For prisoners who "choose not to conform to institutional demands, or if they cannot recognize their 'best interests', then punishment and constraint are not far away" (Crewe et al., 2014). Community release might be delayed or they might have to remain on the induction programme longer and their progression delayed, as described by James:

...OMU [Offender Management Unit] won't contact you or seek you out... It's your responsibility to contact them and find out what you need to do and submit the forms, otherwise your progression and going out will be delayed.

'Coercive responsibilisation' is an apt term to encapsulate the responsibilising of prisoners as shaping prisoner adaptation, culture and prisoner social life in distinctive ways. Building this concept upon the theorisation of Foucault (1977), Crewe (2011, p. 515) argues that power is "diffuse and decentralised, 
operating in a manner that is 'light' but anonymous, demanding without seeming coercive, everywhere but nowhere". Study participant reflections shed light on the confusion caused during the induction process:

I'm all for being left alone to do stuff... but I still needed some support and information to get me to the point where I could, and I didn't get it (Rich).

I've been in closed conditions for years where you get told what to do and when to do it and you have to ask for everything... Now I've come here, and it's the complete opposite, it's hard to adjust... They don't make allowances for that or make that transition easier... You can't just change years and years overnight (Paul).

The softening of penal power through responsibilisation and the use of peers does not mean that the pains of imprisonment have disappeared. Although responsibilisation is welcomed, Rich and two other interviewees agree that it was constructed inappropriately and excessively. The prisoners felt there should have been more structure and guidance provided as part of the programme with a more receptive and accessible induction team. As such, the pains of imprisonment have shifted with these local level establishmentspecific issues characterized by the tick-box culture. The prisoners reported the deleterious impact of issues including the revocation of liberty, the abuse of staff authority, the menacing approach of other prisoners, the severance of family ties, and the deconstruction of their emotional well-being (also see Jewkes, 2005). They also reported a distinct lack of support based upon the assumption of inherent knowledge about the prison due to having been in custody in other establishments. By responsibilising prisoners, staff and peers are allowed the time to fulfil self-serving motivations and/or observe the tick box culture. As Steve notes:

You've been in prison long enough now to know how it works so you'll get the hang of things here soon enough was what the peers and screws told me.

This is a dangerous assumption because reported conditions across establishments vary and the dynamics of prison life differ on all levels, and 
are experienced differently depending on the context of each prison. The differences require mentorship, whether official or not, as Rich explains:

Luckily I knew a few fellas from my last prison, and they showed me the ropes and what I needed to do... No one else did.

Although the prisoners interviewed reported receiving a good level of peer support, it is essential to state that the majority said they gained this support not through the 'official channels' of the Induction Peer Support Workers, nor the Induction Prison Officers, but rather from informal networks of friendships and allegiances built up through their time spent in the prison system. Interviewees articulated that this was due to the lack of engagement and motivation by staff to operate at a level that addressed the prisoners' needs.

Interviewees also mentioned a general perception of disinterest from both staff and peers that led to a degree of mistrust with regard to supporting their best interests. There is a clear overall suggestion that peer support works in assisting the induction process, but not in the manner intended. Effective support is, in fact, garnered from peers outside of the programme. Prisoners were forced to migrate away from the programme that is intended to support and develop both them and their knowledge of the establishment to help them adapt and undertake a form of self-responsibilisation. In the experience of the prisoners interviewed, responsibilisation left them in a state of ontological uncertainty (Giddens, 1984) by tying them into their own subjection. The application of penal power in this manner creates significant insecurities; when faced with consistent uncertainty, prisoners are prone to perceive everything as loaded with meaning and view everything as a test or a threat.

Throughout the interviews, prisoners described prison as an institution that obstructs one's progress, while simultaneously presenting the illusion of offering to help. The widespread comments from participants about "hoops to jump through" (Paul) and "obstacles put in our way" (Rich) are indicative of "an encounter that is one-sided, almost designed to trip you up" (Crewe, 2011, p. 514).

'Tightness' is an aspect of the multi-faceted concept of 'weight'. However, "the shape and distribution of the penal burden have shifted, like a sack of sand remoulding itself across the body of its bearer. There are more levers 
of compliance and regulation, and therefore, more points where the weight is felt" (Crewe, 2011, p. 524). While the pains of imprisonment can be reduced to some degree, pain is intrinsic to the experience of incarceration. These pains will merely manifest themselves in alternate forms and different contexts as a result of various applications of power and operationalisation, rather than being eliminated from the prison experience. As Crewe and colleagues (2011, p. 512-513) muse, the reconfiguration of penal power in prisons in England and Wales has "worked alongside established pains in determining the experience of imprisonment, but they are different in their sources, their feel and their effects". The pains of imprisonment experienced will display variability due to the differentiation between establishments, their security category, regime, location and demographic, as well as how they are operated.

This is an example of a failed policy and a failure to properly implement policy. There is a clear lack of commitment to upholding the policy mandates or meeting prisoner needs due to both an apparent disregard for prisoner safety and well-being, and because the staff and peers do not have the resources necessary for proper implementation. While policy states that insiders should be given the time, knowledge, and support of prison staff and peer supporters, the exploration of this notion against the backdrop of responsibilisation exposes alarming deficiencies in the realm of information sharing and knowledge management, which I expand upon further in the next section.

\section{INFORMATION SHARING OR KNOWLEDGE MANAGEMENT?}

In any organization, an overarching and integral principle is that the "sharing of information at the front-line level is essential in order to provide service users with the right support" (Curtis and Edwards, 2019, p. 355). The induction process is one that should share a raft of information in order to achieve its operational aims and objectives.

Policy states that "governors must ensure that all prisoners are given the information they need on the issues that are important to them" (NOMS, 2015 , p. 2). However, the very use of peers to deliver induction symbolises a more in-depth and complex notion than simply sharing information. Induction Peers should deliver knowledge, rather than just information. 
Knowledge is distinguished as being a "high value form of information" that is "combined with experience, context, interpretation and reflections" (Davenport et al., 1998, p. 43). One of the fundamental purposes of utilizing peers during induction delivery is to go beyond simple information sharing and introduce their critical first-hand experience to more effectively promote better prisoner outcomes for those entering a custodial establishment. As Gupta and colleagues (2000, p. 17) advance, it is "an opportunity to find, select, organise and disseminate and transfer important information and expertise necessary for dynamic learning". Such learning is part of the wider induction process.

However, as Davenport and colleagues (1998, p. 43) have recognized, it is a difficult process to "successfully transfer [knowledge] from one person to another". They stipulate that the motivation to "create, share and use knowledge is an intangible critical success factor for virtually all knowledge management" (ibid). Reflecting upon the self-serving motivations of staff and peers reported, it becomes clear that this has manifested into the induction process to its detriment and indicates poor knowledge management. Steve asserts:

They've been here [in the prison] ages, and the reason they're meant to be doing the job is to help us... They know what we need to know, but they can't be bothered to share it with us...

A key challenge to the management of the peer-led induction model appears to be, as Gupta and colleagues (2000, p. 19) recognize, "how to convince, coerce, direct or otherwise get people to share their information". As evidenced already, the insiders have the knowledge, but often choose not to share it; some of the reasons for this relates to motivational issues such as disinterest and poor staff culture. There is arguably a culture among the insiders and, to a certain degree, the staff that diminishes the effectiveness of knowledge sharing and learning processes. Andy explains the impact of such disinterest:

They need to give us more time and support.... Time don't cost nothing... The fact they didn't have the time for me made me feel lower than I already was and completely lost... Made me feel even more depressed. 
The induction programme appears to follow some principles of "knowledge conversion" (Gupta et al., 2000). This is firstly operationalized through the process of socialisation whereby interactive classroombased induction components involve the sharing of experiences through observation, imitation and practice. There are eleven separate classroombased induction sessions in which information related to various aspects of prison life is shared.

Secondly, there is the conversion of tacit knowledge whereby that which is learned in these classroom-based sessions is presented in written formats. This may take the form of notes the prisoner mentee may take or the literature that is issued to them. Both of these mechanisms capture knowledge in an explicit output. However, there were issues with this process, as Rich shares:

They were throwing info at us, which was good I guess, but the only problem was, I didn't have a real idea what was relevant to me or not... It wasn't clear or explained proper.

Thirdly, there is the issue of dissemination which involves the copying and distribution of explicit knowledge. This is arguably achieved in the induction intervention through the provision of induction packs and literature. While there may be deficiencies in the level of detail and the relevance of the information when contrasted to prisoner needs, the provision of explicit knowledge does nonetheless take place as Rich observes:

There were some leaflets and info booklets in about the different talks on top of the induction timetable and paperwork we got.

The governing PSI states that prisoners must be placed on an appropriate induction and "as far as possible, induction staff should confirm that prisoners understand the information they have been given and know where to seek further guidance" (NOMS, 2015, p. 9). Despite this key objective, unintended outcomes were often the reality:

I was on edge all the time... I didn't have a clue what was going on around me and I didn't get the help I needed to understand it, or the so-called help I got was not what I needed and didn't answer the questions I had... It just 
ended up making me ask more questions no one could or would answer either so I just got more and more anxious and worried (Paul).

Furthermore, the PSI governing induction states that "[p]risoners with wide custodial experience are likely to need less input than those comparatively new to prison, but staff should be aware that some prisoners may not retain information for very long and will need reminding" (NOMS, 2015, p. 8). However, the provision of information to those with custodial experience was seemingly reduced to the total absence of assistance, as expressed by Steve:

Just cos I've been around the block (different prisons) don't mean I know it all or should be expected to... Each prison is different, but they just expected me to know it and get on with it.

A central design parameter to be considered for any service is to ask, "For whose benefit is this service intended?" Given the findings directly applicable to the peer-led induction as proposed by Curtis and Edwards (2019, p. 358), it is argued that "the least successful [information sharing initiatives] have been those designed and imposed from a central bureaucratic perception of the needs of individuals and those committed to assisting them". There have been numerous examples in the findings from those interviewed that categorically and unanimously indicate that this indeed is the case. Rich explains how the induction model is far from a needs-driven model:

Maybe they thought it was what we needed [information], but it weren't the right stuff for me and I didn't get what I needed when I needed it.

The above ought not to be surprising. Crime control institutions have repeatedly failed to achieve their manifest goals (Foucault, 1977). The problem is not merely that the apparatus of 'criminal justice' fails to work. In some instances, the mechanisms introduced to achieve said goals counterproductively create iatrogenic outcomes that make things worse. This is the case with the induction programme, as noted by Rich:

All it did was make me feel more anxious... My anxiety was already bad being in a new place and that [induction] and it just made things worse. 
The PSI dictates that "prisoners are given information and prisoners understand how to access support and facilities available to them in this establishment" (NOMS, 2015, p. 7). Despite this intention, the prisoners interviewed expressed anxiety and concerns surrounding issues related to bullying and safety in the new establishment and were actively seeking supportive reassurances that these concerns were not an ongoing issue. However, the prisoners expressed that these reassurances were not received.

The safer custody induction component was scheduled to be a 30-minute 'Safer Custody' talk, but was significantly shorter and did little to mitigate Andy's anxiety. He explains:

I was worried about bullying and violence 'cos there ain't that many screws in open prison... All they told me was that violence ain't a problem and if it was or if I had any concerns to go see a rep... They didn't tell me what they did or how they deal with it... Just made me more anxious then to go and speak to a prisoner rep who I don't know about my personal stuff made me feel anxious.

Despite the dominant negative discourse concerning the model offered at the establishment, there are also positive perspectives that have been identified through the empirical investigation. Prisoner interviewees all expressed the idea that peer-led induction does have the potential to work if the necessary changes are made.

It's a great idea in principle and I've actually seen it work in other prisons really well, and its helped me settle in and reassure me in other prisons, and calm my anxiety, but they ain't got it set up right here to do it, that's all (Paul).

If they did what we needed then it would be really helpful (Rich).

A prominent and overarching theme identified in all of the findings is that the prisoner participants unanimously express the perspective that the induction model on offer is not an appropriate needs-driven one. They state that the lack of relevant information and content coupled with ineffective delivery only serves to reinforce the anxiety of the prisoner, negatively impacting 
their well-being during the transition to the establishment. This is evident in Steve's assessment of the initiative:

It just made me more stressed and worried about stuff... Just sat up questions with no answers running through my head... I was on a tightrope.

This reality sits in stark contrast to the intended outcome of the induction intervention; the current offering clearly fails to meet its aims. Induction must be a bespoke intervention that is the product of collaborative work between the service user and provider, as detailed by Andy:

They need to sit down with us and ask us what would help us settle better... If they did that and gave us what we wanted to know then I would have felt so much better.

At a time when a tailored package of support, care and information should be provided, there are glaring deficiencies and iatrogenic outcomes identified in these areas to the detriment of prisoner well-being.

\section{CONCLUSION}

The research detailed above provides evidence that the peer-led induction intervention fails to take the form of a needs-driven model. It is illustrative of programmatic iatrogenic effects with the overarching impact being that those subject to induction suffer as a result of the peer-led intervention. Both transfer and transition to a new establishment are critical junctures during which the mental health and well-being of prisoners are both particularly vulnerable and fragile, amplifying and exacerbating the negative emotions frequently exhibited by a large amount of prisoner populations. All prisoners interviewed gave accounts of experiencing a great deal of anxiety, fear and stress. These negative emotions were predominately related to concerns regarding their safety, separation and distance from family and support networks, lack of support, and uncertainty over their custodial existence. They reported that these concerns, issues, and experiences went unsupported and were not addressed despite the detrimental effect on their well-being. 
There is the strong presence of a tick-box culture as demonstrated by both the prison staff and mentors involved in the induction process. Mentees consistently cite a lack of appropriate motivation, alongside the prioritization of self-serving agendas of both prison staff and peer mentors, as negatively impacting their induction experience. Prison staff point to time constraints as limiting their ability to carry out a comprehensive and needs-driven model. They also concede that they can only manage to do the basics. Although, mentees unanimously identify this as an excuse to explain away motivational issues, it must be acknowledged there are austere conditions that cannot be discounted. The mentees suggest that these conditions and motivational issues among prison staff contribute to the creation and reinforcement of a prisoner hierarchy.

The concept of responsibilisation encapsulates a substantial aspect of the induction programme with the motivational aspect of those involved in its provision serving as an underpinning feature of this concept. However, the responsibilisation of the prisoner was not a light or soft application of power, but rather one that loomed overhead as coercive responsibilisation. The study anticipated the strong presence of the 'weight' of imprisonment. However, it became apparent that it was not so much the 'weight' of imprisonment that was experienced by those experiencing transfer, transition and the induction intervention, but rather it was 'tightness' that was the most prominent manifestation of the pain of imprisonment experienced by the mentees. Without answers to important questions, their mind gets agitated, angered, fatigued, and burns itself into a crisis or stalls entirely. This was often the case for the minds of the prisoners interviewed when describing their experience of the induction intervention and the many questions it failed to answer for them.

The study demonstrated that effective induction is more than just an information-sharing vehicle. It is a 'knowledge management' endeavour that relies upon the first-hand experience of peers to deliver an effective induction. However, it is a delicate proposition. The combination of the absence of needs-driven content and the lack of appropriate delivery of the intervention in the contextual backdrop of variable motivation and managerial competence means reality rests in stark contrast to the initiative's intended aims and objectives.

Yet, it must be restated that study participants affirmed that peer support has the potential to improve prisoner well-being in the context of peer-led 
induction and mitigate the pains of imprisonment associated with transfer and transition into a new custodial setting. However, this potential will continue to not be realized within the structure of the current model due to its failure to be an appropriately constructed, motivated and operationalised needs-driven model. Sadly, it will continue to result in a detrimental effect on prisoner well-being. Change is needed for the benefit of prisoners entering new institutions and society more broadly to which most captives will eventually return.

\section{REFERENCES}

Allison, Eric (2017) "There's a mental health crisis in our prisons, yet the justice secretary is silent", The Guardian - December 20. Retrieved from https://www. theguardian.com/commentisfree/2017/dec/20/prisoners-mental-health-self-harmdeaths-jails-liverpool.

Bean, Philip (1980) Punishment: A Philosophical and Criminological Inquiry, Oxford: Martin Robertson.

Beyens, Kristel, Philippe Kennes, Sonja Snacken and Hanne Tournal (2015) "The Craft of Doing Qualitative Research in Prisons", Crime and Justice Journal, 4(1): 66-78.

Cohen, Stanley (1988) Against Criminology. New Brunswick (NJ): Transaction.

Cohen, Stanley (1982) "Western Crime Control Models in the Third World: Benign or Malignant?", Research in Law, Deviance and Social Control, 4: 85-119.

Crewe, Ben (2011) "Depth, Weight, Tightness: Revisiting the Pains of Imprisonment", Punishment and Society, 13(5): 509-529.

Crewe, Ben and Alison Liebling (2017) "Reconfiguring Penal Power", in Alison Liebling, Shadd Maruna and Lesley McAra (eds.), The Oxford Handbook of Criminology (6th edition), Oxford: Oxford University Press, pp. 990-1024.

Crewe, Ben, Alison Liebling and Susie Hulley (2014) "Heavy-light, Absent-present: Rethinking the Weight of Imprisonment", British Journal of Sociology, 65(3): 387-410.

Curtis, Stephen and John Edwards (2019) "Improving Public Services by Sharing the Right Information", Public Money and Management, 39(5): 355-358.

Davenport, Thomas, David De Long and Michael Beers (1998) "Successful Knowledge Management Projects", Sloan Management Review, 39(2): 43-57.

Davies, Brian (1994) "The Swansea Listener Scheme: Views from the Prison Landings", The Howard Journal of Criminal Justice, 33(2): 125-135.

Devilly, Grant, Laura Sorbello, Lynne Eccleston and Tony Ward (2005) "Prison-based Peer-education Schemes", Aggression and Violent Behavior, 10: 219-240.

Dilulio Jr., John (1987) Governing Prisons: A Comparative Study of Correctional Management, New York: Free Press.

Downes, David (1988) Contrasts in Tolerance: Post-War Penal Policy in the Netherlands and England and Wales, Oxford: Oxford University Press.

Ehly, Stewart and Enedina Vazquez (1998) "Peer Counselling", in Keith Topping and Stewart Ehly (eds.), Peer Assisted Learning, Mahwah (NJ): Erlbaum, pp. 217-235. 
Fletcher, Del and Elaine Batty (2012) Offender Peer Intervention: What Do We Know?, Sheffield: Centre for Regional Economic and Social Research. Retrieved from https://www4.shu.ac.uk/research/cresr/sites/shu.ac.uk/files/offender-peerinterventions.pdf.

Foucault, Michel (2002) "The Subject of Power", in James D. Faubion (ed.), Power: Essential Works of Foucault 1954-1984, London: Penguin, pp. 326-348.

Foucault, Michel (1977) Discipline and Punish: The Birth of the Prison, London: Allen Lane.

Fraser, Andrew, Alex Gatherer and Paul Hayton (2009) "Mental Health in Prisons: Great Difficulties But Are There Opportunities?", Public Health, 123(6): 410-414.

Giddens, Anthony (1984) The Constitution of Society: Outline of the Theory of Structuration, Berkeley: University of California Press.

Grotius, Hugo (1625) The Rights of War and Peace. Retrieved from https://oll. libertyfund.org/pages/grotius-war-peace.

The Guardian (2013) "Unthinkable? Hooray for tick-box culture" - May 24. Retrieved from https://www.theguardian.com/commentisfree/2013/may/24/unthinkable-boxticking-approval.

Gupta, Babita, Lakshmi Iyer and Janine Aronson (2000) "Knowledge Management: Practices and Challenges", Industrial Management and Data Systems, MCB University Press, pp. 17-21.

Howells Kevin, Guy Hall and Andrew Day (1999) “The Management of Suicide and Selfharm in Prisons: Recommendations for Good Practice", Australian Psychologist, 34(3): 157-165.

Jail Mail (2018) Safety in Custody Statistics - August.

Jarrett, Christian (2018) "Research into the Mental Health of Prisoners, Digested", The British Psychological Society. Retrieved from https:/digest.bps.org.uk/2018/07/13/ research-into-the-mental-health-of-prisoners-digested/.

Jewkes, Yvonne (ed.) (2007) Handbook on Prisons, Cullompton: Willan.

Jewkes, Yvonne (2005) "Men Behind Bars: "Doing" Masculinity as an Adaptation to Imprisonment", Men and Masculinities, 8(1): 44-63.

Kerish, B.R. (1975) "Peer Counselling", in Ray Hosford and Claude Moss (eds.), The Crumbling Walls: Treatment and Counselling of Offenders, Chicago: University of Illinois Press, pp. 45-57.

Liebling, Alison (2014) "Postscript: Integrity and Emotion in Prisons Research", Qualitative Inquiry, 20(4): 481-486.

Liebling, Alison (1999) "Prisoner Suicide and Prisoner Coping", Crime and Justice, 26: 283-359.

Liebling, Alison (1992) Suicides in Prison, Oxford: Routledge.

Liebling, Alison and Helen Arnold (2004) Prisons and Their Moral Performance: A Study of Values, Quality and Prison Life, Oxford: Clarendon Press.

Liebling, Alison and David Price (1999) “An Exploration of Staff-Prisoner Relationships at HMP Whitemoor", Prison Service Research Report, No. 6, London: HMPS.

McHugh, Martin. (1995) "Managing Suicidal Behaviour among the Prison Population", Journal of the Royal Society of Health, 115(2): 117-119.

Mesmer-Magnus, Jessica and Leslie DeChurch (2009) "Information Sharing and Team Performance: A Meta-Analysis", Journal of Applied Psychology, 94(2): 535-546. 
McMahon, Maeve (1992) The Persistent Prison? Rethinking Decarceration and Penal Reform, Toronto: University of Toronto Press.

Ministry of Justice [MOJ] (2018) Freedom of Information Request 180804002 email to Edwin Schreeche-Powell - September 8.

Munro, Eileen (2010) The Munro Review of Child Protection: Final Report - A Child-centred System. Retrieved from http://www.education.gov.uk/munroreview/ downloads/GovernmentResponset oMunro.pdf.

National Offender Management Service [NOMS] (2015) "Early Days in Custody: Reception In, First Night in Custody, and Induction to Custody". Retrieved from https://www.justice.gov.uk/downloads/offenders/psipso/psi-2015/psi-07-2015-pi06-2015-early-days-in-custody.pdf

Parliament (2017) Prison Reform: Governor Empowerment and Prison Performance, London. Retrieved from https://slidelegend.com/prison-reform-governorempowerment-and-prison-performance_59e748d91723dd0d81571006.html.

Peay, Jill (2017) "Mental Health, Mental Disabilities and Crime", in Alison Liebling, Shadd Maruna and Lesley McAra (eds) The Oxford Handbook of Criminology (6th Edition), Oxford: Oxford University Press, pp. 639-662.

Snow, L. and Kathy Biggar (2006) "The Role of Peer Support in Reducing Self-harm in Prisons", in Greg Dear (ed.), Preventing Suicide and Other Self-harm in Prison, New York: Palgrave, pp. 153-166.

South, Jane, Anne-Marie Bagnall, Claire Hulme, James Woodall, Roberta Longo, Rachael Dixey, Karina Kinsella, Gary Raine, Karen Vinall-Collier and Judy Wright (2014) A Systematic Review of the Effectiveness and Cost-effectiveness of Peerbased Interventions to Maintain and Improve Offender Health in Prison Settings - Report for the National Institute for Health Research (NIHR) Health Services and Delivery Research (NIHR HS\&DR) Programme Project.

Sykes, Gresham (1958) The Society of Captives: A Study of a Maximum-Security Prison, New Jersey: Princeton University Press.

Teers, Rebecca (2005) "Evaluation Summary", in Prisoner Peer Support: Good Practice Guide for Insiders Peer Support Schemes, HMP Safer Custody Group. Retrieved from http://www.lemosandcrane.co.uk.

Walby, Kevin (2014) "Pains of Imprisonment: Everyday Deprivation and the Meanings of Post-Prison", Journal of Prisoners on Prisons, 23(1): 85-87.

Woodall, James (2018) “Offender Peer Support in Prisons Research”, email to Edwin Schreeche-Powell - June 12.

World Health Organisation [WHO] (1998) Mental Health Promotion in Prisons. Retrieved from http://www.euro.who.int/_data/assets/pdf_file/0007/99016/ E64328.pdf.

\section{ABOUT THE AUTHOR}

Edwin Schreeche-Powell is an Assistant Lecturer and $\mathrm{PhD}$ Candidate in Criminology at the University of Kent, Canterbury. His research interests include prisons and penal policy, with a focus on mental health and wellbeing, 
safer custody and power-sharing initiatives in prisons, as well as a broader interest in punitiveness within the criminal justice system in Western Europe. Ed holds a 1st Class BSc (Hons) in Criminology and Psychology, as well as an MA with Distinction from the University of Kent. Ed was awarded a Vice-Chancellor's Scholarship for his $\mathrm{PhD}$, which is a multi-site investigation of prison induction interventions in the England and Wales. Ed has recently contributed an auto-ethnographic chapter to the book Degrees of Freedom (Policy Press) regarding the experience of distance learning in custodial settings and the interaction with the offender identity, as well as an article published in The Conversation surrounding the transformative power of higher education initiatives in prisons. Ed harnesses his lived experience as a former long-term prisoner to inform his research and teaching. He can be reached by email at E.Schreeche-Powell@kent.ac.uk. 